\title{
A suitable analytical formula for the $K$ shell ionization cross section of carbon and potassium atoms by electron impact
}

\author{
Salim H. Al-Shamma Muzahim I. Azawi \\ Department Physics / College of Education \\ University of Mosul
}

$\begin{array}{cc}\text { Received } & \text { Accepted } \\ 20 / 09 / 2011 & 01 / 02 / 2012\end{array}$

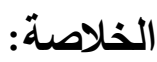

k تم في هذه الدراسة اقتراح صيغة رياضية مقبولة للمقاطع العرضية الأيونية للقشرة للارتين الكربون (Z=6) و البوتاسيوم (Z=19) بطريقة تصادم الالكترونات. اعتمدت هذه الدراسة على نتائج المستحصلة من قبل الباحث سبل لحساب الدقاطع العرضية الأيونية لهذه

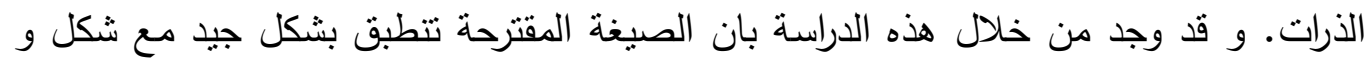

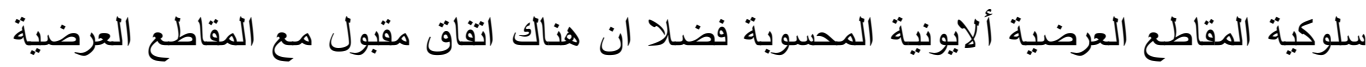
ألايونيه المحسوبة عند الطاقات الاكترونية الواطئة من قبل الباحث سبل.

\section{Abstract:}

In this study an analytical expression proposed for $\mathrm{k}$ shell ionization cross section for two atomic elements $C(Z=6)$ and $K(Z=19)$ due to electron impact had been investigated. This study is based on the analysis of calculated $\mathrm{k}$ shell ionization cross section. The proposed analytical expression had been found to fulfill the task of the fitting shape and behavior of the Sbell $\mathrm{k}$ ionization cross section database with an acceptable agreement in the values of the cross section at low incident energies.

\section{Introduction:}

There are two well known mechanism of the ionization in atomic collision, impact ionization and ionization via excitation of autoionization states. Ionization due to electron impact is one of the important challenges facing several fields of physics and numerous technical applications, such as radiation physics, electron energy loss spectroscopy, transmission electron spectroscopy, Auger electron spectroscopy, for material characterization and for electron probe microanalysis. 
Reviews concerning measurement and theoretical calculations of inner-shell ionization cross sections have been given by Powell $(1,2)$. According to these reviews, it appears that both measurements and calculations have been carried out mostly of the k shells for high incident electron energies, where as there are few measurements and calculations for the $\mathrm{k}$ shells and energies near ionization threshold.

The cross section of removal of an electron from atomic $\mathrm{k}$ shell (which call simply $\mathrm{k}$ shell ionization cross section) due to electron impact have been investigated by an experimental and theoretical methods. Experimentally, measurements of $\mathrm{k}$ shell ionization cross section for a number of atomic elements due to electron impact have been performed by $(3,4,5)$. Theoretically, an empirical formula had been proposed to describe the $\mathrm{k}$ shell ionization cross section for a few atomic elements due to electron impact has been carried out by $(6,7,8,9,10)$. An analytical expression for $\mathrm{k}$ shell ionization cross section for neutral atoms by electron impact for a wide range of incident electron incident energies has been proposed by $(11,12)$.

In this work, an analytical formalism for $\mathrm{k}$ shell ionization cross section will be suggested for $\mathrm{C}$ and $\mathrm{K}$ atoms.

\section{Theory:}

In order, to obtain an analytical formalism for $\mathrm{k}$ shell ionization cross section for $\mathrm{c}$ and $\mathrm{k}$ atoms, a curve fitting tool has been applied to plot the database from the literature with high resolution figure. After plotting each figure for each element using Sbell formalism (10), then the first derivative of the data where calculated by mathlab with the help of the code Runge - Kutta fourth order of the suggested analytical formalism in this work which is given by the following formula:

$$
\frac{\partial \sigma}{\partial E}=\exp \left(-2\left(E-w_{o}\right)^{2} / w_{1}+\operatorname{sqrt}\left(E-w_{2}\right) / w_{3}\right.
$$

Where: $\mathrm{w}_{\mathrm{o}}$ is the cross section at energy $\mathrm{E}_{\mathrm{o}}$

$\sigma$ is the cross section

$\mathrm{E}_{\mathrm{o}}$ is the average energies

$\mathrm{w}_{1}, \mathrm{w}_{2}$ and $\mathrm{w}_{3}$ are fitting parameters.

This formula will be used to interpret the calculated results in the next section.

\section{Results and discussions:}

An analytical formula as indicated in equation (1) is used in this work to describe the $\mathrm{k}$ shell ionization cross section for $\mathrm{C}(\mathrm{Z}=6)$ and $\mathrm{K}(\mathrm{Z}=36)$ atoms over a wide range of incident electron energies.

The calculated database of $\mathrm{k}$ shell ionization cross section as given by Sbell for $\mathrm{c}$ and $\mathrm{k}$ atoms are drawn in the top of figures (1 and 2), where those obtained by equation (1) suggested to this work for above mentioned atoms are drawn in the bottom of figures (1 and 2) respectively. 
As seen from figure (1) that the proposed analytical formula describes very well the shape and behavior of the calculated $\mathrm{k}$ cross section for $\mathrm{c}$ atoms except that the calculated $\mathrm{k}$ shell ionization cross section at energy $(10 \mathrm{keV})$ given by Sbell seems to be higher than that of given by proposed analytical formula.

Similarly, the proposed analytical expression describes well the shape and behavior of the calculated $\mathrm{k}$ shell ionization cross section as observed from figure (2). the calculated cross section at the energies $10^{2}$ and $10^{3} \mathrm{keV}$ seems to be higher than obtained by the proposal analytical expression.

In order to match the calculated database and the result obtained by proposed expression, one can need to adjust very carefully the fitting parameters that are mentioned in equation (1).

As matter of fact experimental data usually recorded with large step between points where on the other hand, theoretical data where usually with very small step size give a huge number of points on the gtaph.
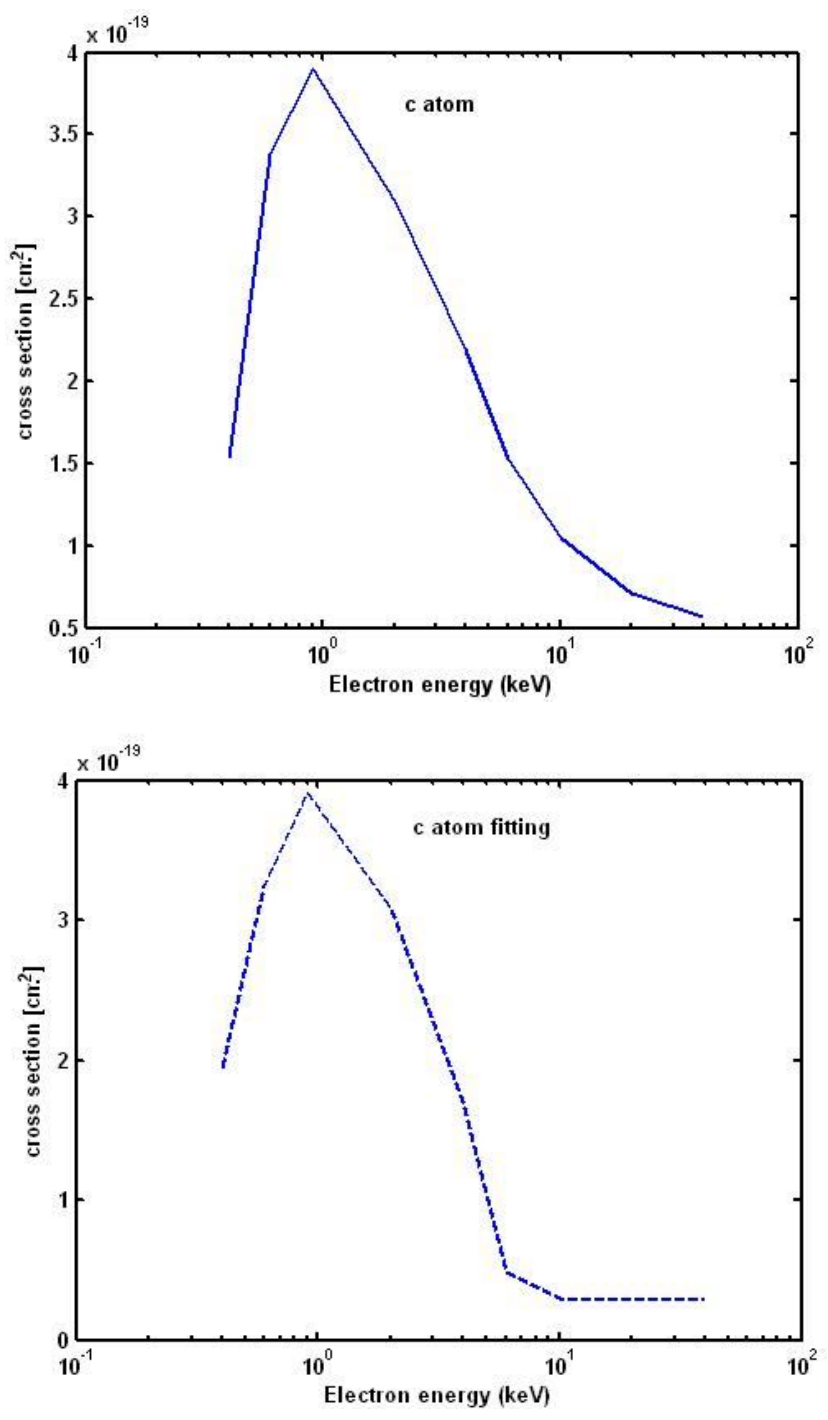

Fig. (1): $k$ shell ionization cross section as a function of incident energy for c atom. The calculated and present data for cross section are drawn in the top and bottom figures. 

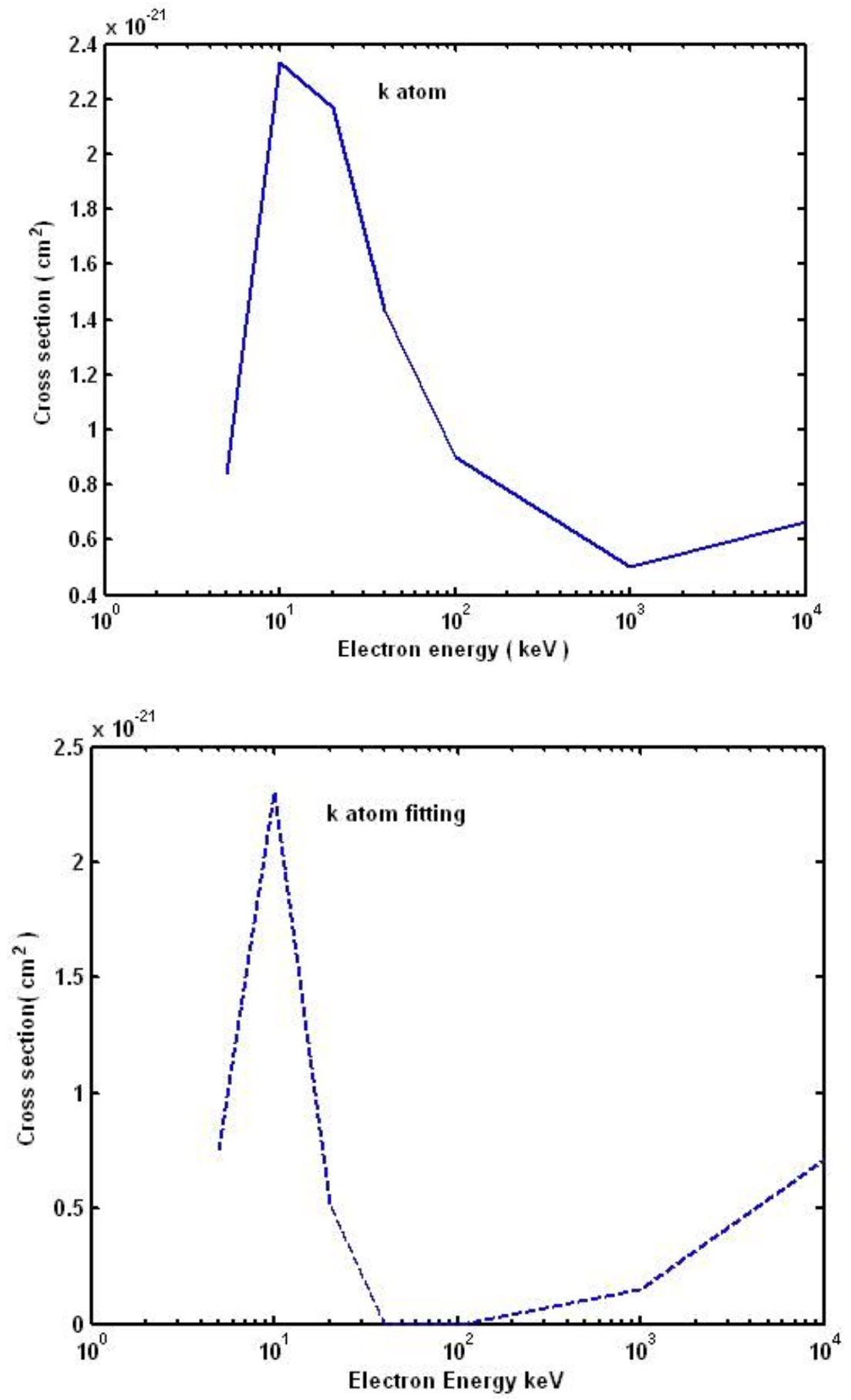

Fig ( 2 ) k shell ionization cross section as a function of incident energy for $\mathrm{k}$ atom. The present and calculated data for cross section are drawn in the top and bottom figures respectively. 


\section{Conclusion:}

The results obtained from the analytical formula suggested to this work represents a convenient and acceptable approach to get $\mathrm{k}$ shell ionization cross section for two selected $\mathrm{C}$ and $\mathrm{K}$ atoms.

\section{References:}

1) Powell, C. J. (1976) Rev. Mod. Phys. 48, 33.

2) Powell, C. J. (1985) Electron impact ionization, ed. T.D. Mark and G. H. Dunn (Springer - verlag Berlin).

3) Liovet, X., Merlet, C. and Salvat, F. (2000) J. Phys. B: At. Mol. Phys. 33, $3761-3772$.

4) Merlet, C., Liovet, X. and Salvat, F. (2004) Phys. Rev. A67, 032708.

5) Baydas, E., Orthan, E. and Buyukyidiz, M. (2009) Turk, J. Phys. 33, $311-316$.

6) Casnati, E., Tatari, A. and Baraldi, C. (1982) J. Phys. B. At. Mol. Phys. 15, $155-167$.

7) Ashley, J. C. (1982) Electron spectros. Relat. phenom. 28, 1977.

8) Tang, C. H., An, Z. Fan, X. Q, Luo, Z. H. (2001) Chin. Phys. Letter. $48,8,1052$.

9) Deutsch, H., Becker, K., Gstir, B. and Mark, T. D. (2002) Int. J. of mass spectroscopy $213.5-8$.

10) Talukder, M. R., Bose, M. R. and Takamur, S. (2008) Int. J. mass spectroscopy, 269, 118. 